\title{
MANIFESTAÇÕES PATOLÓGICAS EM SISTEMAS PREDIAIS HIDROSSANITÁRIOS: ESTUDO DE CASO EM ESCOLAS DO MUNICÍPIO DE CRATEÚS - CE
}

\author{
Pathological manifestations in plumbing systems: case study \\ in schools in the municipality of Crateús - CE
BEZERRA, Amanda Jéssica Alves ${ }^{1}$; BATISTA, Tatiane Lima²; CÂNDIDO, Luis Felipe ${ }^{3}$; COSTA, Heloina Nogueira da ${ }^{4}$

Recebido em 16 de julho de 2021, aprovado em 05 de setembro de 2021, publicado em 18 de novembro de 2021

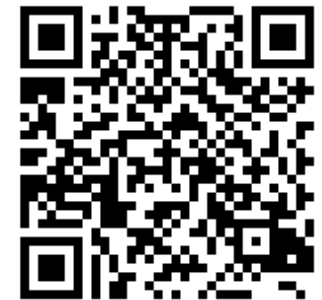

Palavras-chave: Instalações prediais hidrossanitárias;

Inspeção predial;

Patologia das edificações.

Keywords:

Plumbing Facilities;

Building inspection;

Pathology of buildings.
RESUMO: Este trabalho teve como objetivo diagnosticar as condições dos sistemas prediais de água fria, esgoto sanitário e águas pluviais de edificações públicas escolares. Para tanto, realizou-se uma inspeção, empregando os preceitos da Avaliação Durante Operação (ADO), em três edificações escolares no município de Crateús-CE, semiárido nordestino. Identificou-se que as manifestações patológicas com maior incidência nos sistemas prediais de água fria, esgoto sanitário e águas pluviais são vazamentos, mau cheiro e vazamentos e infiltrações, respectivamente. Pôde-se observar que o sistema predial de águas pluviais foi o que apresentou o maior índice de inconformidades. Com isso, esta pesquisa ampliou o diagnóstico sobre patologias relacionadas aos Sistemas Prediais Hidráulicos e Sanitários (SPHS) nesse tipo de edificação, alertando para a necessidade da melhoria da fiscalização e dos processos que envolvem o projeto, execução e manutenção desses sistemas.

\begin{abstract}
This study aimed to diagnose the conditions of fresh water, sewage drainage and rainwater harvesting plumbing systems in public school buildings. For that, an inspection was carried out, using the precepts of the Evaluation During Operation (ADO), in three school buildings in the city of Crateús-CE, northeastern semiarid region. It was identified that the pathological manifestations with the highest incidence in fresh water, sewage drainage and rainwater harvesting systems are leaks, bad smells and leaks and infiltrations, respectively. It could be observed that the rainwater harvesting system was the one with the highest rate of non-conformities. Thus, this research has expanded the diagnosis of pathologies related to plumbing systems in this type of building, alerting to the need to improve inspection and processes that involve the design, execution and maintenance of these systems.
\end{abstract}

\section{CONTATO DOS AUTORES:}

${ }^{1}$ BEZERRA, Amanda Jéssica Alves: Universidade Federal do Ceará, BR 226, km 4, Lado par. Bairro José Rosa. Crateús-CE, amandaarrezeb@gmail.com

2 BATISTA, Tatiane Lima: Universidade Federal do Ceará; tatianelima.eng@gmail.com

${ }^{3}$ CÂNDIDO, Luis Felipe: Universidade Federal do Ceará; candido@crateus.ufc.br

${ }^{4}$ COSTA, Heloina Nogueira da: Universidade Federal do Ceará; heloina@crateus.ufc.br 


\section{INTRODUÇÃO}

Os Sistemas Prediais Hidráulicos e Sanitários (SPHS) compreendem subsistemas de uma edificação para condução, captação, transporte e armazenagem adequada de líquidos (GNNIPER, 2010). Dentre eles estão o Sistema Predial de Água Fria (SPAF), Sistema Predial de Esgoto Sanitário (SPES) e o Sistema Predial de Águas Pluviais (SPAP).

De acordo com Carvalho Júnior (2018) a maior parte das manifestações patológicas das construções estão relacionadas com as instalações hidráulicas prediais. Dentre as principais manifestações patológicas nos SPHS estão os vazamentos, mau cheiro, ruídos, entupimentos, transbordamento de calhas e contaminação da água (CARVALHO JÚNIOR, 2018). Como ressaltam Teixeira et al. (2011), elas costumam causar transtornos e desconfortos.

Esses problemas não ocorrem somente em edificações residenciais, mas também em edificações de uso coletivo, dentre as quais pode-se destacar as escolas. Tendo em vista que os usuários dos espaços das edificações de ensino passam, em média, um terço de seu dia no interior da escola, a qualidade desses ambientes afeta aspectos relacionados a saúde, higiene e conforto, influenciando no processo de ensino-aprendizagem (BRASIL, 2006).

Porém, ao se revisitar a literatura sobre SPHS verificou-se a incipiência de estudos em prédios públicos escolares, o que justifica o presente trabalho que teve como questão de pesquisa: quais as condições dos sistemas prediais de água fria, esgoto sanitário e águas pluviais de edificações públicas escolares?

Assim, este trabalho desenvolve um estudo em prédios escolares públicos com objetivo de diagnosticar as condições dos SPHS por meio da identificação das manifestações patológicas mais recorrentes nos sistemas. No estudo, tomou-se três edificações escolares no município de Crateús-CE, semiárido nordestino. O estudo contribui com a ampliação das evidências empíricas sobre os SPHS em edificações públicas escolares. Além disso, é bom ressaltar que no contexto da pandemia de COVID-19, o funcionamento adequado dos SPHS é indispensável ao retorno às aulas presenciais, o que aumenta ainda mais a relevância desse estudo.

\section{METODOLOGIA}

Este trabalho seguiu os preceitos da Avaliação Durante Operação (ADO) (ALMEIDA, 1994), tendo como objeto de estudo os sistemas prediais de água, esgoto e águas pluviais de prédios escolares. Essa metodologia traz uma proposta de etapas para avaliar sistemas prediais em operação, conforme descrito a seguir.

\subsection{Seleção e caracterização das amostras}

O município de Crateús está localizado na região centro-oeste do estado do estado do Ceará, divisa com o estado do Piauí, na microrregião chamada de Sertão de Crateús (CEARÁ, 2019) e possui uma população total estimada de 75.159 habitantes para o ano de 2020 (IBGE, 2020). Segundo o Censo Escolar de 2020, o município possui 74 escolas de educação básica (INEP, 2020) e 53 delas está sob responsabilidade da Prefeitura Municipal de Crateús. Tomou-se três dessas unidades, aqui designadas como Escola A, Escola B e Escola C, cujas principais características são apresentadas na Tabela 1. Os critérios definidos para escolha das amostras foram escolas com idades diferentes e o acesso para realização das visitas, a fim de representar melhor a situação das escolas do município. 
Tabela 1 - Descrição das escolas selecionadas

\begin{tabular}{cccc}
\hline Características & Escola A & Escola B & Escola C \\
\hline Ano de construção & 1987 & 2007 & 2013 \\
\hline Idade (anos) & 33 & 13 & 7 \\
\hline Ano da última reforma & 2008 & 2020 & - \\
\hline Número de alunos & 382 & 396 & 277 \\
\hline Número de professores & 26 & 15 & 20 \\
\hline Número de funcionários da limpeza & 5 & 3 & 3 \\
\hline Séries & 60 ao 9o ano & 60 ao 9o ano & Ensino Infantil \\
\hline \multicolumn{5}{l}{}
\end{tabular}

\subsection{Levantamento documental}

Para a Escola A foi disponibilizado apenas o projeto arquitetônico. Para a B, os projetos arquitetônico e elétrico e para a $\mathrm{C}$ os projetos hidrossanitário, estrutural, arquitetônico e elétrico. Para esta última, identificou-se divergências entre projeto e execução para os sistemas hidrossanitários. Nenhuma das escolas possuía As Built.

\subsection{Inspeção local}

O levantamento em campo consistiu na inspeção visual e na realização de testes. Foi elaborado um checklist para cada sistema predial inspecionado e outro para verificação do estado de conservação e condições de operação dos aparelhos sanitários, com base no trabalho de Silva e Paixão (2016). Durante a inspeção, foi realizado o registro fotográfico das manifestações patológicas encontradas e foram realizados os testes de Sucção (OLIVEIRA, 1999) e Corante (CARVALHO JÚNIOR, 2018) para identificação de vazamentos não visíveis no alimentador predial e nas bacias sanitárias, respectivamente.

\subsection{Análise das manifestações patológicas encontradas}

Foram elaboradas fichas técnicas para as principais manifestações patológicas encontradas com as seguintes informações: registro fotográfico, aspectos observados, causas prováveis, medidas de prevenção e recomendações. Os resultados foram comparados para as três escolas a fim de identificar recorrências, diferenças e influências das características das edificações nos resultados.

\section{RESULTADOS E DISCUSSÕES}

A Tabela 2 apresenta um sumário das manifestações identificadas para os aparelhos sanitários.

Ao total foram inspecionados 189 itens relacionados aos equipamentos sanitários, dos quais 61 apresentaram alguma manifestação patológica (32\% deles). O equipamento sanitário que apresentou maior quantidade de problemas foi a torneira (13 manifestações) seguido da válvula de descarga. Visualmente, a bacia sanitária com caixa acoplada não apresentou nenhum problema. É importante destacar que foram identificados vazamentos e/ou gotejamentos em duchas, registros, bacias sanitárias, bebedouros e torneiras, o que pode acarretar desperdício de água e aumento das despesas. O teste do corante identificou 
vazamentos não visíveis em $24 \%$ das bacias sanitárias inspecionadas. Verificou-se, também, que a maioria dos problemas identificados são de simples correção.

Tabela 2 - Manifestações identificadas

\begin{tabular}{|c|c|c|c|c|c|c|c|c|c|c|}
\hline \multirow{3}{*}{$\begin{array}{l}\text { Aparelho/ } \\
\text { Equipamento } \\
\text { sanitário }\end{array}$} & \multicolumn{4}{|c|}{ Quantidade } & \multicolumn{4}{|c|}{ Manifestações } & \multirow{3}{*}{ Descrição } & \multirow{3}{*}{$\begin{array}{l}\text { Método } \\
\text { de } \\
\text { inspeção }\end{array}$} \\
\hline & \multicolumn{3}{|c|}{ Escola } & \multirow{2}{*}{$\Sigma$} & \multicolumn{3}{|c|}{ Escola } & \multirow{2}{*}{$\Sigma$} & & \\
\hline & A & B & C & & A & B & $\mathrm{C}$ & & & \\
\hline $\begin{array}{c}\text { Bacia sanitária } \\
\text { (Louça) }\end{array}$ & 5 & 2 & 18 & 25 & 2 & 1 & 2 & 5 & Rachadura e Sem tampa & Visual \\
\hline $\begin{array}{c}\text { Bacia sanitária } \\
\text { (Flexível) }\end{array}$ & 5 & 2 & 0 & 7 & 1 & 1 & 0 & 2 & Vazamento e dobrado. & Visual \\
\hline $\begin{array}{l}\text { Bacia sanitária } \\
\text { (Caixa acoplada) }\end{array}$ & 5 & 1 & 0 & 6 & 0 & 0 & 0 & 0 & - & Visual \\
\hline $\begin{array}{c}\text { Bacia sanitária } \\
\text { (Caixa de Descarga) }\end{array}$ & 0 & 1 & 0 & 1 & 0 & 1 & 0 & 1 & Falta de puxador. & Visual \\
\hline $\begin{array}{c}\text { Bacia sanitária } \\
\text { (Válvula de Descarga) }\end{array}$ & 0 & 0 & 18 & 18 & 0 & 0 & 11 & 11 & $\begin{array}{l}\text { Quebrada e não } \\
\text { funciona }\end{array}$ & Visual \\
\hline $\begin{array}{l}\text { Bacia sanitária } \\
\text { (Vazamentos) }\end{array}$ & 5 & 2 & 10 & 17 & 1 & 0 & 3 & 4 & Vazamento. & $\begin{array}{l}\text { Teste do } \\
\text { corante }\end{array}$ \\
\hline Ducha & 2 & 3 & 14 & 19 & 0 & 1 & 9 & 10 & $\begin{array}{c}\text { Gotejamento; } \\
\text { vazamento e não } \\
\text { funciona. }\end{array}$ & Visual \\
\hline Registro & 2 & 3 & 14 & 19 & 1 & 1 & 2 & 4 & Vazamento e ausente. & Visual \\
\hline Torneira & 10 & 2 & 34 & 46 & 1 & 0 & 12 & 13 & $\begin{array}{l}\text { Mal fixada; vazamento; } \\
\text { gotejamento e } \\
\text { entupimento. }\end{array}$ & Visual \\
\hline Cuba & 9 & 1 & 17 & 27 & 1 & 1 & 8 & 10 & Sem sifão e sem coluna. & Visual \\
\hline Bebedouro & 2 & 1 & 1 & 4 & 1 & 0 & 0 & 1 & $\begin{array}{c}\text { Gotejamento e } \\
\text { entupido. }\end{array}$ & Visual \\
\hline Total & 45 & 18 & 126 & 189 & 8 & 6 & 47 & 61 & - & - \\
\hline
\end{tabular}

Analisando por sistema, no Sistema Predial de Água Fria (SPAF) observou-se maior incidência de vazamentos. Esse resultado corrobora com Cremonini (1988) que em seu estudo concluiu que a manifestação patológica com maior incidência nos SPHS em unidades escolares foram vazamentos nas instalações hidráulicas. É interessante destacar que mais de 30 anos depois, esse problema ainda é recorrente nesse tipo de edificação. No Sistema Predial de Esgoto Sanitário (SPES) a manifestação patológica com maior incidência foi o mau cheiro. A causa provável é a ausência de um sistema de ventilação e posicionamento inadequado do sifão, inconformidades que foram identificadas na inspeção. Barros, Silva e Paes (2015), ao realizarem uma análise das condições dos sistemas de água e esgoto de 4 escolas públicas, identificaram que dentre as principais manifestações patológicas nesses sistemas estão: mau cheiro, vazamentos, entupimentos e empoçamentos. Resultados semelhantes aos deste trabalho. Já no Sistema Predial de Águas Pluviais (SPAP), observou-se uma maior incidência de vazamentos e infiltrações. Foi identificada a inexistência ou uma quantidade insuficiente de elementos como calhas, condutores horizontais, e pontos de drenagem nas lajes e pisos. 
A Figura 1 apresenta o índice de inconformidades encontradas em cada SPHS a partir da aplicação do checklist. Esse valor indica a porcentagem das inconformidades listadas que foram identificadas em cada escola e sistema.

Figura 1 - Índice de inconformidades nos SPHS

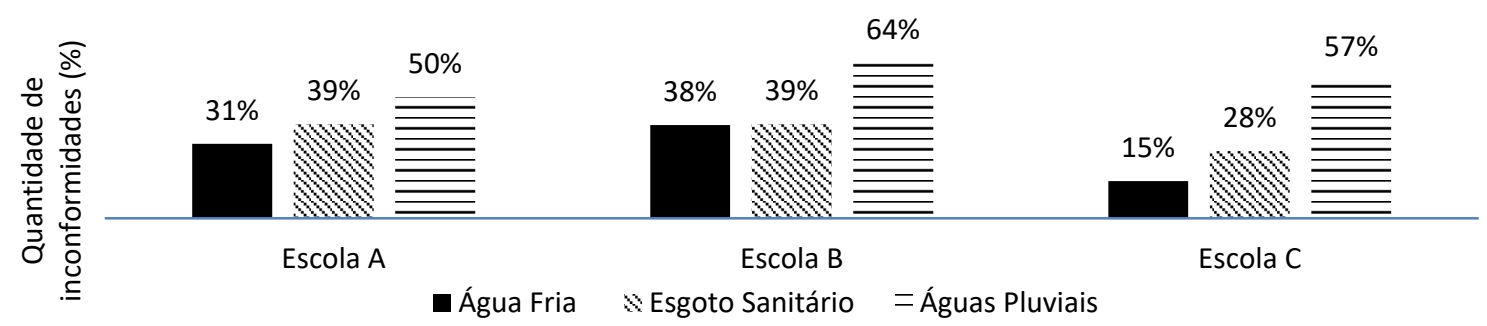

Fonte: Os autores (2021).

Observa-se que a escola que apresentou o maior índice médio de inconformidades foi a $B$ (47\%), que foi a que possuiu maior índice de inconformidades no SPAF e no SPAP. Este resultado divergiu do esperado, uma vez que a edificação possuía apenas 13 anos no momento da pesquisa, enquanto a Escola A possuía 33 anos. Além disso, a Escola B passava por uma reforma, e, portanto, não foi possível investigar todas as áreas da edificação, logo, o esperado era que não apresentasse tantas inconformidades quanto as outras. Com relação ao Sistema Predial de Esgoto Sanitário (SPES), as escolas A e B apresentaram o mesmo número de inconformidades. Outro resultado divergente do esperado aconteceu no SPAP, pois a Escola C, com apenas 7 anos, apresentou mais inconformidades do que a escola mais antiga, com 33 anos. Algo que pode ser observado a partir do gráfico da Figura 1 é que o SPAP foi o que apresentou os maiores índices de inconformidades nas três escolas.

O Quadro 1 apresenta um exemplo de ficha técnica que foi desenvolvida para as principais manifestações patológicas encontradas.

\section{Quadro 1 - Ficha técnica para mau cheiro}

\begin{tabular}{|c|l|}
\hline $\begin{array}{c}\text { Aspectos } \\
\text { observados }\end{array}$ & $\begin{array}{c}\text { Mau cheiro na área externa proveniente das caixas de inspeção de esgoto; parte de uma } \\
\text { tubulação que entrava na caixa estava quebrada. }\end{array}$ \\
\hline $\begin{array}{c}\text { Possíveis causas } \\
\text { Medidas }\end{array}$ & $\begin{array}{l}\text { Vedação inadequada da caixa de esgoto e ausência do sistema de ventilação. } \\
\text { de gases. Além disso, toda instalação de esgoto deve ter tubulação de ventilação, de } \\
\text { acordo com a ABNT NBR 8160/1999, para lançar os gases das tubulações para a atmosfera. }\end{array}$ \\
\hline $\begin{array}{c}\text { Recomendações } \\
\text { Substituição das tampas de concreto e aplicação de sistema eficiente de vedação. Execução } \\
\text { do sistema de ventilação. }\end{array}$ \\
\hline
\end{tabular}

Fonte: Os autores (2021). 


\section{CONSIDERAÇÕES FINAIS}

Este trabalho teve por objetivo analisar a condição dos SPHS de edificações públicas escolares. Para tanto, realizou-se inspeção em três escolas públicas do município de Crateús, o que permitiu identificar as manifestações por aparelho, por sistema e seus estados de conservação.

O SPAP foi o que mais apresentou manifestações patológicas e também o mais negligenciado, no que diz respeito a constatação da não existência de alguns de seus elementos. As manifestações patológicas mais frequentes nas escolas foram vazamentos nas instalações hidráulicas, mau cheiro e presença de vazamentos e infiltrações causados pela chuva. A ausência de as built dificultou a inspeção dos sistemas, visto que boa parte de seus elementos se encontravam embutidos nas paredes e pisos.

Cabe destacar que esta pesquisa, embora apresente um panorama da cidade de Crateús, contribuiu para o avanço científico de estudos sobre patologias em sistemas prediais hidrossanitários em edificações públicas escolares à medida que ampliou o diagnóstico sobre a problemática nesse tipo de edificação, alertando para a necessidade da melhoria da fiscalização e dos processos que envolvem o projeto, execução e manutenção desses sistemas. É importante ressaltar que o desempenho dos elementos constituintes dos SPHS impacta diretamente no conforto e bem-estar dos usuários das edificações escolares e se faz ainda mais importante no contexto atual de pandemia.

\section{REFERÊNCIAS}

ALMEIDA, G.G. Avaliação Durante Operação (ADO): Metodologia aplicada aos Sistemas Prediais. Dissertação de Mestrado, Escola Politécnica da Universidade de São Paulo, 1994.

ASSUNÇÃO, R. S. et al. Levantamento de manifestações patológicas nos sistemas prediais hidráulicos -estudo de caso em uma edificação da UFG. 2011. Trabalho de Conclusão de Curso (Graduação em Engenharia Civil) - Universidade Federal de Goiás.

BARROS, F. de A., SANTIAGO SILVA, D. V. C., \& PAES, R. P. de. Instalações Prediais Hidráulicas e Sanitárias em escolas públicas: Patologias e satisfação dos usuários. REEC - Revista Eletrônica De Engenharia Civil, 11(2), 2016.

BRASIL. Ministério da Educação. Secretaria de educação básica. Parâmetros Básicos de Infraestrutura para Instituições de Educação Infantil. Encarte 1, 2006.

CARVALHO JÚNIOR, R. de. Patologias em Sistemas Prediais Hidráulicos-Sanitários. 3. ed. São Paulo: Editora Blucher, 2018. 226 p.

CEARÁ. Planejamento participativo e regionalizado: caderno regional Sertão dos Crateús. Secretaria de Planejamento e Gestão do Estado do Ceará (SEPLAG). Fortaleza: SEPLAG, 2019.

CREMONINI, R.A. Incidência de manifestações patológicas em unidades escolares na região de Poro Alegre. Recomendações para projeto, execução e manutenção. Porto Alegre, 1988. Dissertação (mestrado). Universidade Federal do Rio Grande do Sul, 1988.

GNIPPER, S. F. Diretrizes para formulação de método hierarquizado para investigação de patologias em sistemas prediais hidráulicos e sanitários. Mestrado em Engenharia Civil. Universidade Estadual de Campinas. São Paulo, 2010. 
INSTITUTO NACIONAL DE ESTUdOS E PESQUISAS EDUCACIONAIS ANÍSIO TEIXEIRA (INEP). Censo Escolar, 2020.

OLIVEIRA, L. H. de. Metodologia para a implantação de programa de uso racional da água em edifícios. 1999. Tese (Doutorado em Engenharia Civil) - Universidade de São Paulo, [S. I.], 1999.

SILVA, M. H. A. da; PAIXÃO, T. C. R. Proposição de ferramenta de avaliação de projetos hidráulicos e sanitários prediais. 2016. Trabalho de conclusão de curso (Graduação em Engenharia Civil) Universidade Federal de Goiás, São Paulo, 2016.

TEIXEIRA, P. de C. et al. Estudo de Patologias nos Sistemas Prediais Hidráulicos e Sanitários do Prédio do Ciclo Básico II da Unicamp, Revista Eletrônica de Engenharia Civil, v. 1, n. 2, p. 34-50, 2011. 